\title{
Acculturative Experiences Among Indonesian Graduate Students in US Higher Education: Academic Shock, Adjustment, Crisis, and Resolution
}

\author{
Amirul Mukminin ${ }^{\mathrm{a}}$ \\ ${ }^{a}$ University of Jambi, Indonesia
}

\begin{abstract}
The purpose of this qualitative inquiry was to describe and understand the lived experiences of the acculturative process of Indonesian graduate students at an American public research university. The theoretical frameworks of Oberg's (1960) Culture Shock Model and Berry and his colleagues' (1987) and Berry's (2006) Acculturation Stress Model were used to guide this study. Data for this study were collected through a demographic background survey, in-depth interviews, and focus group discussions with Indonesian graduate students. The demographic data were analyzed descriptively. The interviews and focus groups data were analyzed using within-case and cross-case displays and analyses (Miles and Huberman 1994). Five salient themes and sub-themes that emerged were: academic shock, adjustment, crisis, resolution, and what helps/does not help. Implications and strategies for professionals and scholars who work with international students in practice, education, and policy are discussed. In addition, strategies to promote Indonesian graduate students' academic and social success in graduate programs are included. Suggestions for future research are also discussed.
\end{abstract}

\begin{abstract}
Abstrak
Penelitian kualitatif ini bertujuan untuk mendiskripsikan and memahami pengalaman hidup mahasiswa pascasarjana asal Indonesia selama proses akulturasi di sebuah perguruan tinggi riset di Amerika Serikat. Teori Syok Budaya dari Oberg (1960) dan Teori Stres Akulturasi dari Berry (2006) dan Berry dan koleganya (1987) digunakan sebagai landasan atau kerangka teoritis dalam penelitian ini. Data dalam penelitian ini dikumpulkan melalui survey demografis, wawancara, dan diskusi fokus grup. Data demografis dianalisa secara deskriptif. Sedangkan, data wawancara dan diskusi fokus grup dianalisa memakai within-case and cross-case displays and analyses dari Miles dan Huberman (1994). Lima tema utama dengan sub-tema yang muncul adalah: academic shock, adjustment, crisis, resolution, and what helps/does not help. Implikasi dan strategi bagi para professional dan pendidik yang berhubungan dengan mahasiswa internasional baik yang berkenan dengan hal-hal praktis, pendidikan, dan kebijakan dibahas dalam artkel ini. Juga dibahas strategi untuk mempromosikan keberhasilan mahasiswa Indonesia dalam kehidupan akademik dan sosial di perguruan tinggi di Amerika Serikat. Saran untuk penelitian dimasa yang akan datang juga didiskusikan.
\end{abstract}

Key Words: Lived Experiences, Acculturative Process, Acculturation Stress, Culture Shock, Indonesian Graduate Students

\section{Introduction}

From the late 1940s, American post-secondary institutions have become the destinations of international students to pursue their educational careers (Institute of International Education [IIE] 2010). According to the Open Doors report issued once a year by IIE with support from the U.S. Department of State's Bureau of

*Corresponding author. Address: Faculty of Education-FKIP, University of Jambi, Jalan Raya Jambi-Ma. Bulian km. 15 Mendalo Darat 36361, Jambi, Indonesia.

Email: amirmuk@yahoo.com; am08ae@my.fsu.edu.
Educational and Cultural Affairs, in the 2008-2009 academic year, the number of international students at American post-secondary institutions was 671,616; in the 2009-2010 academic year, the number of international students was 690,923 (IIE 2010, 2011). Despite the increases in the international student population attending higher education in the United States, the number of Indonesian students attending higher education in the United States has been declining. The report shows that of the 671,616 international students from the 2008-2009 academic year, 7,509 (1 percent) were from Indonesia, and of the 690,923 international students from the 2009-2010 academic year, 6,943 were from 
Indonesia. Furthermore, of the 723,277 international students from the 2010-2011 academic year, 6,942 were from Indonesia. The decline in the number of Indonesian students in US higher education is not a recent trend, however. The number of Indonesian students in the US dropped from 13,282 in the 19971998 academic year (Marklein 2011) to 6,942 in 2010-2011 (IIE 2011).

The continuous decline in the number of Indonesian students in US higher education has become an important topic for the United States and Indonesian governments. In order to double the number of Indonesian students studying in the US within five years, President Barack Obama and Indonesian President Susilo Bambang Yudhoyono signed a Joint Declaration in November 2010 (Association of Public and Land-Grant Universities 2011). However, the decline of Indonesian students studying at US institutions of higher education raises important questions: Is the decline in enrollment of Indonesian students in US higher education related to acculturative problems or difficulties they face during their acculturative process at their host universities? If it is related to the acculturative problems, to what extent do the acculturative problems or stressors influence the decline in enrollment of Indonesian students in US higher education, which ultimately hinders the goals of the Joint Declaration? Or is the issue of decline related to other factors that have not been researched?

Previous research has suggested that most international students encounter challenges and difficulties during the acculturative process that result from inter-culturally continuous contacts that cannot be resolved quickly by simply adjusting or adapting to the academic and social culture at American institutions. Due to a lack of extensive exposure to the academic and social culture of the US, as well as significant differences in language, cultural values and communication styles, Asian international students appear to experience more acculturative stress and culture shock than do students from other regions (Abe, Talbot, and Geelhoed 1998; Zhai 2002; Heggins and Jackson 2003; Yeh and Inose, 2003; Wilton and Constantine 2003; Poyrazli, Kavanaugh, Baker, and Al-Timimi 2004; Trice 2004; Li and Gasser 2005; Lee and Rice 2007; Fritz, Chin, and DeMarinis 2008; Nilsson, Butler, Shouse, and Joshi 2008; Sato and Hodge 2009).

While a substantial number of previous studies have addressed the acculturative problems experienced by many international students, most of them have focused on international students in general or have grouped all Asian international students from different nationalities into one category. Additionally, most of these studies tend to place Indonesian students in the same group as other Asian students (Zhai 2002; Trice 2004; Fritz, Chin, and
DeMarinis 2008; Sumer, Poyrazli, and Grahame 2008). Despite the fact that Asian countries are geographically closest to Indonesia, they are not culturally homogeneous. As a result, these studies might not be able to identify unique and individual acculturative experiences of Indonesian international students, thus obscuring our understanding of their acculturative problems and challenges.

Little research, however, specifically explores the lived experiences of Indonesian graduate students coming from diverse backgrounds and experiences in US institutions. This study is an attempt to fill a gap in the international student and Asian international student acculturation literature and to inform the lack of literature and information on Indonesian graduate students' acculturative experiences in US higher education. The following research questions guided this study in an attempt to understand and describe the lived experiences of the acculturative process of Indonesian graduate students in the US:

- What have Indonesian graduate students from diverse backgrounds and experiences (e.g., Muslim and NonMuslim students) experienced academically and socially during their acculturative process resulting from continuous, first hand contact with a different culture?

- What are the major sources of acculturative problems or stressors, or the major causes of culture shock leading to acculturative stress experienced by Indonesian graduate students?

- How have Indonesian graduate students from diverse backgrounds and experiences dealt with those acculturative stressors or major causes of culture shock during the first term and over time at their institutions?

\section{Why Focus on Indonesian International Students}

As international students who have traveled long distances from their country to the US in their pursuit of greater knowledge, skills, and experience, Indonesian students bring with them their own cultures and expectations. This long journey shows that their enthusiasm and expectations for studying at American universities are high. Many of them will spend years on a campus pursuing their university degrees. They expect to experience a much higher quality of education at American universities than at those in their own country. In addition, they expect to experience lives in relatively comfortable environments, academically and socially.

However, when Indonesian students come to the US, their expectations might not easily be met, due in part to the absence of "familiar cues" one often experiences when entering a foreign environment (Oberg 1960, 142). For Indonesian students 
transitioning to the US educational environment, they may meet several challenges including cultural, social, and academic dissimilarities since they may not be aware of unfamiliar academic, cultural, and social rules, norms, traditions, and values that rule interaction and communication in US universities. Indonesian students may experience "change events in their lives that challenge their cultural understandings about how to live. These change events reside in their acculturation experiences" (Berry 2006, 294). These changes may lead to what Berry (2006) called "acculturative stress," which is "a stress reaction in response to life events that are rooted in the experience of acculturation” (294).

As the findings from several studies on international students indicate, there are several stressors or factors that influence the acculturation experience of international students to a new culture (Wan, Chapman, and Biggs 1992; Perrucci and Hu 1995; Abe, Talbot, and Geelhoed 1998; Wilton and Constantine 2003; Yeh and Inose 2003; Poyrazli, Kavanaugh, Baker, and Al-Timimi 2004; Trice 2004; Klomegah 2006; Fritz, Chin, and DeMarinis 2008; Sumer, Poyrazli, and Grahame 2008). Among these stressors are English proficiency, gender, age, race/ethnicity, social support, patterns of social contact (i.e., with whom do students socialize most), and length of stay. The combined effect of these stressors may affect their acculturation process to the new cultures during their transition to college and during their college years.

Although a number of previously qualitative and quantitative studies on international students have well documented the sources of difficulties or stressors, including social, cultural, and academic barriers that international students face in the US, most of these studies have focused on international students in general. In these studies, international students are grouped into one category (e.g., by region, race/ethnicity, or educational level), which makes it impossible to see the international students' unique and individual acculturative experiences. Additionally, most of these studies are survey based. Although, the survey-based reports are useful for understanding how international students perceive their acculturation process, the findings give us limited information on how international students actually experience their acculturative process and how sources of difficulties or stressors actually influence their academic and social life during their transition to college and during their college years.

From the perspective of the acculturation stress model (Berry, Kim, Minde, and Mok 1987; Berry 2006), every group and individual who comes to a new culture goes through acculturative experiences or processes in different ways, and there are several moderating factors (e.g., demographic, social, and/ or psychological characteristics of an individual) that may influence the extent and direction of the relationships among the acculturative experience, stressors, and acculturative stress. Therefore, there is a critical need to focus on a single group and to provide in-depth understanding of stressors through rich descriptions of what a single group has experienced academically and socially during their acculturative process resulting from continuous, first hand contact with a different culture in their first term and over time at their institution.

Additionally, there have been a number of studies examining the acculturative issues of Asian international students. Most of these studies, however, look at Asian students as a pan-Asian group (Chen, Mallinckrodt, and Mobley 2002; Zhai 2002; Trice 2004; Li and Gasser 2005; Fritz, Chin, and DeMarinis 2008; Nilsson, Butler, Shouse, and Joshi 2008; Sumer, Poyrazli, and Grahame 2008; Sato and Hodge 2009). While these studies focus on a particular region, they do not account for the fact that Asian countries are culturally heterogeneous. They obscure the fact that Asian international students at US colleges and universities are from diverse countries where languages, values, lifestyles and customs vary to a great extent. According to Heggins and Jackson (2003), the diversity within and among Asian international students suggest that each group of students may possess dissimilar issues and needs. Consequently, generalizations regarding Asian international students without paying attention to within-group differences may bring about faulty conclusions. Therefore, although the findings of these studies might offer some useful insight into what Asian international students have experienced during their acculturative process in the US, the major sources of acculturative problems or culture shock and the strategies students use to deal with such issues may not be homogenous since international students come from diverse backgrounds and experiences.

In response to this, there have been several recent studies examining the acculturative issues of Asian international students in the United States from countries such as China (Wei, Mallen, Heppner, Yao Ku, Hsin Liao, and Feng Wu 2007), Taiwan (Ying 2005), South Korea (Lee, Koeske, and Sales 2004; Lee 2009), and Japan (Toyokawa and Toyokawa 2002). Given that research on the acculturative experience of students from Indonesia is comparatively limited, however, there is cause for concern that the experience of Indonesian students in US higher education will be mistaken as similar to those of students from other Asian countries.

An earlier study on Indonesian students conducted by Adeng Chaedar Alwasilah (1991) found that Indonesian students in the US experienced academic and social challenges such as writing research papers, making oral presentations, working with American students, consulting with American advisors, using 
English, thinking in terms of Indonesian culture and applying it to American situations, and understanding American culture and values. While Alwasilah's (1991) study is useful for understanding what Indonesian students experienced during their acculturative process in the US two decades ago, the world has changed considerably since 1991, which further justifies the need for such research.

The world has experienced dramatic cultural, social and political changes that have altered issues of content, access to, and means of communication, thereby influencing acculturation of Indonesian students at higher education institutions in the US. For instance, the horrific tragedy of September 11, 2001 (9/11) has changed many people's perception of Islam and Muslims, including Muslims from Indonesia in the US and Europe. Despite the tension this tragedy created between Western countries and Arabs and Muslims, it also increased the visibility of Islam and Muslims. Many people sought out books and information on Arabs and Muslims, and there were many radio and TV programs and lectures on Islam and Muslims, which shed light on the reality that Muslims and Islam varies by country, ethnic group, and even individuals. In addition, in Indonesia, since the fall of Suharto's regime in 1998, which is called the era of reformation (reformasi), there have been dramatic cultural, social, and political changes. These have been characterized by the removal of restrictions on getting information from outside the country, by greater freedom of speech, and by a more open and liberal political, social and cultural environment. Other changes relate to globalization and information technology. In terms of culture, "globalization promotes integration and the removal not only of cultural barriers but many of the negative dimensions of culture. Globalization is a vital step toward both a more stable world and better lives for the people within it" (Rothkopf 1997, 39), suggesting that globalization has led to the growth of cross-cultural contacts and has revolutionized people's way of living through transnational networks, social movements, and relationships in many areas. Also, due to technological advancements in Internet access and in mediums of communication such as Facebook, email, YouTube, Google, and Wikipedia, information about the cultures of other countries is now easily accessible worldwide, which may greatly facilitate Indonesians getting knowledge on other cultures.

With the dramatic cultural, social and political changes that have taken place in the past two decades, the degree of unfamiliarity and uncertainty that Indonesian graduate students face in their new academic and social culture in the US might now be significantly lower. Therefore, by examining students from similar cultural backgrounds, my goal is to describe and understand the lived experiences of the acculturative process of Indonesian international students. Particularly, to what extent acculturative stressors or culture shock challenge Indonesian graduate students from diverse backgrounds and experiences during their first term and throughout their studies at a US institution.

\section{Theoretical Framework}

The theoretical framework for this study is the intersection of two frames of thought. The first theoretical underpinning is Kalervo Oberg's (1960) Cultural Shock Model. The second theoretical frame is John W. Berry and his colleagues' (1987) and Berry's (2006) Acculturative Stress Model.

The term culture shock, identified as a reaction to a change in a new cultural environment, was first introduced in the late 1950s by anthropologist Kalervo Oberg who was born in Canada and became a US citizen in 1944. Oberg (1960) believed that culture shock was "precipitated by the anxiety that results from losing all our familiar signs and symbols of social intercourse” (177). Individuals entering a new cultural environment may lose all familiar and common signs, symbols, cues, social roles, interpersonal contacts, and support, leading individuals to experience anxiety, frustration, and helplessness. The well-known signs, symbols, and cues might include words, gestures, facial expressions, customs, or norms. Oberg (1960) analogized individuals who entered a new culture to "a fish out of water. No matter how broad-minded or full of good will you may be, a series of props have been knocked from under you, which is followed by a feeling of frustration and anxiety” (177). The stages of culture shock when entering a new culture are typically categorized into four different phases: the honeymoon or traveler phase, the crises phase, the adjustment and gradual recovery phase, and the adaptation phase (Oberg 1960; Winkelman 1994).

Although Oberg's (1960) Culture Shock Model is useful to look at the stages the participants of this study have gone through during their acculturation processes at their host institution, the model does not clearly address factors or variables such as nature of the larger society, type of acculturating group, modes of acculturation, and demographic, psychological, and social characteristics of individuals. When individuals enter a new culture, these variables will not only influence the degree of culture shock but will also influence individual reactions and responses to sources of culture shock.

Due to the limitations of Oberg's (1960) Culture Shock Model, the current study incorporates Berry and his colleagues' (1987) and Berry's (2006) Acculturative Stress Model in order to enhance understanding of the participants' acculturation processes at their host university. Acculturation is defined as a process of adapting to a new culture, including the behavior and internal changes that 
occur during the acculturating process (Berry et al. 1987; Berry 2003, 2006). Acculturative stress refers to general and cultural stress reactions associated with transitioning to a new culture. Berry argued (2006) that at the individual level, when acculturation experiences cause problems, one of the acculturation outcomes is "acculturative stress," which happens as "a stress reaction in response to life events that are rooted in the experience of acculturation” (294). At this point, acculturating individuals experience changes in routine patterns of behaviors in their lives, challenging their cultural understanding regarding how to live in a new culture and how to be familiar with new situations of daily life.

However, Berry and his colleagues (1987) concluded that there are two crucial points regarding the relationships among the acculturative experience, stressors, and acculturative stress. First, the relationships "are probabilistic rather than deterministic" (494). They are possible to take place, but not fixed. Second, the relationships among the three depend on a number of moderating factors, including nature of the larger society, type of acculturating group, modes of acculturation, demographic and social characteristics of individual, and psychological characteristics of individual. Each of the moderating factors may influence the extent and direction of the relationships among the acculturative experience, stressors, and acculturative stress, suggesting that every group and individual goes through acculturative experience or processes in different ways. For some acculturating individuals, the acculturative changes in routine patterns of behaviors and internal characteristics in their lives may become stressors, whereas for others, the changes may be benign or may be considered as opportunities (Berry et al. 1987). Both theories were used as lenses to describe and understand the lived experiences of the acculturative process of Indonesian graduate students at a public research university in the United States.

\section{Methods}

Experience is personal and subjective; hence, the quantitative traditions of research such as surveys may not give in-depth information to achieve the purpose of this study. For this study, a qualitative design in the phenomenological tradition was used to describe and understand the lived experiences of the acculturative process of Indonesian graduate students. The key elements of a phenomenological study are to understand how one or more individuals experience a phenomenon and to explore in-depth accounts of experiences and their meanings from participants' personal words, descriptions, reflections, and perspectives on the phenomenon (Patton 1990; Moustakas 1994; Merriam 1998).
John W. Creswell (1998), Clark E. Moustakas (1994), and Michael Q. Patton (1990) suggest that any researcher who wants to use the phenomenological tradition needs to understand the philosophical perspectives behind this tradition. Phenomenology as a philosophical tradition first came from Edmund H. Husserl (1859-1938), a German mathematician and philosopher. According to Patton (1990, 69), Husserl's basic philosophical assumption is that:

We can only know what we experience by attending to perceptions and meanings that awaken our conscious awareness. Initially, all our understanding comes from sensory experience of phenomena, but that experience must be described, explicated, and interpreted. Yet, descriptions of experience and interpretations are so intertwined that they often become one. Interpretation is essential to an understanding of experience and the experience includes the interpretation. Thus, phenomenologists focus on how we put together the phenomena we experience in such a way as to make sense of the world and, in so doing, develop a worldview.

This perspective, Patton (1990) claims, has two implications that are often confusing in qualitative methods. A phenomenological perspective can mean either (1) "a focus on what people experience and how they interpret the world (in which case one can use interviews without actually experiencing the phenomenon oneself) or (2) a methodological mandate to actually experience the phenomenon being investigated (in which case participant observation would be necessary)" (70). This study addresses both aspects of Patton's phenomenological perspective. The first aspect relates to participants of the study by focusing "on what people experience and how they interpret the world” (70). To address this aspect, I interviewed Indonesian graduate students to get in-depth accounts of experiences and their meanings from participants' words, descriptions, reflections, and perspectives on the phenomenon (i.e., acculturation to the US academic and social culture) during their acculturative processes at their host university in a post-9/11 era. The second aspect, "a methodological mandate to actually experience the phenomenon being investigated," (70) applies as well since, as the researcher for this study, I was an international graduate student in the US following 11 September 2011. As a result, I experienced the phenomenon as both an insider and outsider.

\section{Research Site, Sampling Procedures and Participants}

The site for this study was at a public research university in the southern part of the United States that has more than 1,250 
international students, about 78 percent of whom are graduate students from over 100 different countries and regions (International Center 2010). This study was conducted from May to November 2011. At the time of the study, 16 Indonesian graduate students were pursuing a graduate degree at the research site.

For sampling, to identify individual cultural changes and acculturation outcomes necessitates "sampling a population and studying individuals who are variably involved in the process of acculturation” (Berry 2006, 289). For a phenomenological study, the important issue is to describe the meaning of the lived experience from individuals who have experienced the phenomenon under study by collecting information from in-depth interviews with five to 25 individuals (Polkinghorne 1989; Creswell, 2007; Johnson and Christensen 2008). Following Donald E. Polkinghorne's (1989), Creswell's (2007), and Burke Johnson and Larry B. Christensen's (2008) suggestion regarding the number of participants for a phenomenological study, my goal was to recruit all 16 Indonesian graduate students enrolled in the university during the 2010-2011 academic year. Of the 16 students, 13 agreed to participate in the study. Despite the fact that this study was limited to a specific public institution in the US and the sample of Indonesian graduate students participating in the study may not be representative of all Indonesian graduate students in the US, the characteristics of the sample population were very diverse. The diverse characteristics of the participants may make this study relevant across a larger population of Indonesian graduate students in the US, however the results of this study should be interpreted carefully.

Other distinguishing characteristics were gender, type of graduate degree, major, marital status, religion, and previous experience in a foreign country. Eleven participants were male and two were female. Twelve participants were doctoral students and one participant was a master's student. Eight participants were married and five were single. Four participants were Muslim, three were Protestant, five were Catholic, and one participant was Hindu. Prior to coming to the United States, seven participants had visited or lived in another country (e.g., pursued a master's degree, attended conferences, or participated in short courses). Four participants majored in an applied social science and nine participants majored in a hard science. The participants were (pseudonyms) Zulkifli and Mursalin (male doctoral students majoring in an applied science), Adriani (a female doctoral student majoring in an applied science), Sujono (a male master's student majoring in an applied science) Leo, Hamdani, Rojuk, Sabarno, Suhantono, Antoni, Jauhari, and Kamarudin (male doctoral students majoring in a hard science), and Lala (a female doctoral student majoring in a hard science.

\section{IRB Approval Process}

To protect the rights of human participants, approval for the study was granted by the Institutional Review Board (IRB). The researcher also masked the names of people, places, and the research site through the use of pseudonyms for the participants, places, and research site. Participation was voluntary.

\section{Data Collection Procedures}

Data collection consisted of a demographic background survey, two audio recorded in-depth interviews and two focus group discussions. All 13 participants completed a demographic survey during the second week of May 2011. All 13 Indonesian graduate students were asked to discuss their acculturative experiences during their transition to the university and during their university years. In the first round of interviews, each interview lasted between 90 and 120 minutes. For the second round, the interviews lasted between 90 and 100 minutes. Because English is a second language for all participants, the participants were given the option to respond to interview questions in either Indonesian or English. All elected to use English. As a result, any grammatical errors will appear in the interview excerpts provided in the findings section. Individual interviews were conducted prior to the focus group discussions. This was done in order to allow every participant to share his or her personal stories and experiences on acculturation without being influenced by other participants.

I facilitated two focus group discussions with Indonesian graduate students so they could again describe detailed accounts of their experiences of their acculturative experiences. My rationale to do this was to look for information (i.e., experience) that might not have been provided by participants in their individual interviews. The focus group discussions lasted between 90 and 120 minutes. All 13 participants were asked to participate in the first and second focus groups. Initially, eight participants expressed an interest in the first focus group, but five ended up participating due to their academic activities. In the second focus group discussion, of the five participants who initially participated, three joined the discussion.

\section{Trustworthiness}

To establish the "trustworthiness" (Lincoln and Guba 1985, 300 ) of my study or to verify the accuracy of data, findings, and interpretations (Creswell 1998), I completed the following procedures. First, my study undertook prolonged engagement and repeated interviews (Creswell 1998; Merriam 1998). I conducted individual interviews lasting between 90 and 120 minutes. In the 
first round of interviews, 13 students participated. Of those, 12 agreed to be interviewed a second time; Mursalin, a male doctoral student majoring in an applied science, declined because he was busy with his academic activities. Second, I triangulated data through multiple interviews and focus group discussions. Third, member checks were used in order to get participant feedback on the accuracy and credibility of the data, findings, interpretations, and conclusions. In the words of Yvonna S. Lincoln and Egon G. Guba (1985, 314), this is "the most critical technique for establishing credibility.” I arranged a face-to-face meeting with participants to discuss the results of the interviews. Seven participants had time to discuss the findings and provide feedback. Fourth was clarifying researcher bias (Glesne 1998; Marshall and Rossman 1999). From the beginning of this study, I stated who I was and what assumptions drove this research including my past experience, training, biases, and orientation that influenced my interpretation and methods for the study. Last, I provided rich and thick descriptions (Merriam 1998; Creswell 2003) and narratives of Indonesian graduate students' acculturative experiences. This included verbatim examples from the transcribed interviews and focus group discussions.

\section{Data Reduction and Analysis}

The demographic data were analyzed descriptively. The interview and focus group discussions data were first prepared by transcribing the audiotaped interviews. I put the data into computer files and file folders after transcribing the raw data into text. This made it easy to copy and paste a word, a phrase, a sentence, or a paragraph.

The second step was that I immersed myself in the details, getting a sense of the interviews and focus groups data as a whole before I broke them into several parts. This was done in order to "obtain a general sense of the information and to reflect on its overall meaning” (Creswell 2003, 191). At this point, epoche, or bracketing, is important in a phenomenological study. Epoche is a "Greek word meaning to refrain from judgment, to abstain from or stay away from the everyday, ordinary way of perceiving things” (Moustakas 1994, 33). I set my preconceived ideas about the phenomenon aside to best understand it through participants' personal words, descriptions, reflections, and perspectives.

The third step was related to codes, themes, or categories. Matthew B. Miles and Michael A. Huberman (1994) wrote, “coding is analysis" (56), and Johnson and Christensen (2008) stated, "coding is a process of marking segments of data (usually text data) with symbols, descriptive words, or categories” (534). I developed provisional codes based on previous research, my theoretical framework, my research questions, and questions and topics from my interviews before analyzing the data. These provisional codes helped me develop inductive codes and final themes for which I used participants' words or terms.

Finally, to find and describe stressors that the participants of this study faced, I analyzed and reanalyzed the individual interviews and focus group discussions data by using within-case and cross-case displays and analyses (Miles and Huberman 1994) and connected the data with my theoretical framework and my research questions. I used within-case and cross-case displays (Miles and Huberman 1994) consisting of thematic conceptualordered displays, causal network displays, and partially ordered displays to: (1) spread interviews data so as to find and list every significant statement relevant to the topic, to see the patterns and themes, and to deepen understanding and explanation of my data among the cases (participants) and among the emergent themes; (2) to create clusters of meanings by organizing, grouping, or clustering the significant statements among the cases (participants) into themes or meaning units; and (3) to remove or reduce overlapping and repetitive data.

\section{Findings}

The purpose of this study, within the theoretical frameworks of Oberg's (1960) Culture Shock Model and Berry and his colleagues' (1987) and Berry’s (2006) Acculturation Stress Model, was to describe and understand the lived experiences of the acculturative process of Indonesian graduate students at a public research university in the US. As presented in Table 1, five salient themes and their sub-themes emerged from the individual interview and focus group discussions data: academic shock/no honeymoon, adjustment, crisis, resolution, and what helps/does not help? These themes represent common processes Indonesian graduate students encountered throughout their acculturative process during their first term and over time at their host university.

\section{Academic Shock/No Honeymoon Phase}

Within this theme, the findings showed that during their first semester, Indonesian graduate students did not go through Oberg's (1960) honeymoon or traveler phase. Instead, they directly encountered acculturative stressors or stressful life events arising from academic and personal stressors and language issues as a result of continuous contacts with the new culture.

Academic Stressors in the First Semester: Nothing Surprising. Acculturative stress theory says that conflicts between the two cultures experienced by acculturating individuals will become 
sources of difficulty or acculturative stressors (Berry et al. 1987; Berry 2006) or sources of culture shock (Oberg 1960).

Table 1. Themes and Sub-themes for the Acculturative Process of Indonesian Graduate Students

\begin{tabular}{l|l}
\hline Themes & Sub-themes \\
\hline Academic & (1) Academic stressors \\
Shock/No & (2) Language issues \\
Honeymoon & (3) Personal stressors \\
\hline Adjustment & (1) Surprising non-stressors: (a) no sense of \\
& \multicolumn{2}{c}{ cultural or religious discrimination and (b) } \\
& (2) Time to learn and adjust to expectations \\
& (3) Forming supportive relationships in host \\
& (4) Connecting or reuniting with family \\
\hline Crises & (1) Academic crises \\
& (2) Personal crises \\
\hline Resolution & \\
\hline What helps/does & \\
not help? & \\
\hline
\end{tabular}

Due to the unanticipated academic differences in cultural encounters and their continuous contact with the academic culture at their host university, participants in this study reported that the major academic stressors that influenced their acculturation processes during their first semester were academic workload, teaching assistantships, high expectations, performance anxiety, and conflict with non-US faculty. For academic workload, Antoni, a male doctoral student majoring in a hard science, said,

I felt a little bit stressed in the first semester because in my department at that time each professor gave me one assignment every week. So, since I had three classes, then I had to do three assignments a week and they were very difficult for me. So, the problem in the first semester was to adapt to the hard work situation. It required a lot of work and time. It was not like what happened to my home university. I just got three or four assignment in one semester. But here I got homework every week and a lot of work. But, you know as a graduate student, it is my life and I need to overcome those problems.

Lala, a female doctoral student majoring in a hard science also reported that academic workload was challenging in the first semester. She reflected,

When the first time I got here [at her host university] in physics, I mean in the first semester, I couldn't do any homework, it was a lot of homework. I took three courses and each of them had homework every week. You can imagine that every week you do three different kinds of homework. It was really difficult and no time to breathe. I didn't know how to do anything because during the lectures, what professors gave me in the lectures was not exactly what you really need to do your homework. It was not the same, I had to interpret it. So, I didn’t know anything. I was actually in an academic probation.

The second academic stressor that participants who majored in physics reported was that during their first semester at their host university they encountered a stressful situation due to the combination of two responsibilities as a full time graduate student and teaching assistant.

I took 9 credits hours every semester as required for a full time student and I was also a TA [teaching assistant]. The amount of work as a TA like teaching and grading made me stressed. I needed to prepare my teaching material well while I also needed to do my coursework. (Jauhari, a male doctoral student majoring in a hard science)

Non-teaching assistant students also reported that they felt stressed during the first semester as a full time graduate student. For example,

As a full time graduate student, the most difficult semester was the first semester. I could not do anything else except doing my homework and readings. It was shocking and stressful for me. In the first semester, I was worried about whether or not I could achieve the high expectation from faculty members reflected on their syllabus although I believe that professors set high standards to motivate students and this is good, I believe. Here students are expected to be independent in their learning. Twelve hours or four classes are very difficult to do because when you get overload work or burden, you will lose the joy. As a result, you will not do well. That is how I felt in the first semester. If I don't understand, I don't get comprehensive knowledge of the course and I will feel unhappy and stressed. Also, if I don't get good grades, my sponsor will warn me and it makes me worried about it. (Zulkifli, a male doctoral student majoring in an applied science)

Additionally, participants in this study were shocked and anxious with the fact that they should get above 94 out of 100 if they wanted to get an A in every course. Compared to Indonesia, the highest score to get an A is 80 out of 100 . The data indicated that some participants reported that they had a stressful and demanding 
experience related to their professors' high expectations and pressure to perform well during their first semester.

If I did not perform well, I not only disappoint myself, but also my family and my school. I had one professor who set a really high standard in his course and it was very hard for me to achieve in the first semester. I was on academic probation. But, I was determined to change it and after the first semester. (Leo, a male doctoral student majoring in a hard science)

My first semester was crazy. The academic standard here is high. I did have pressure to get good grades in every course. If you take three classes, it means three kinds of homework you will get every week. That was demanding. But, I could handle them at the end. (Sujono, a master's student majoring in an applied science)

Some participants typically reported that they had difficulties with faculty members who come from other countries and who seem to maintain their home culture in American academic culture.

I prefer working with American professors to any other professors from other countries in my university. I got unfair treatment from non-American professors. Actually the unfair treatment did not happen only to me but also to other students who took the classes with those non-American professors. My experience is that non-American professors were not available outside the classroom and when I asked a question, most of them did not take it seriously. I had experience with Chinese and Russian professors. They are very different from American professors. You can only ask specific and best questions. If you ask an easy question, they will ignore you. In my opinion, they think that I should know all things and ask only good questions for them. (Suhantono, a male doctoral student majoring in a hard science)

Language Issues: Struggling more with Four Language Skills than Expected. Indonesian graduate students in this study came from diverse backgrounds and experiences. Although English is not their first language, some of them have studied English since they were kids, some of them pursued their undergraduate or master's degrees in an English speaking country, and some of them have attended several trainings or conferences held in English before coming to the US. However, when they came to their host university, participants reported that they had language difficulties related to listening, speaking (e.g., oral presentation and active class participation), reading, and writing during the first term. This prevented them from communicating with others inside or outside of class.

During the first semester, listening was a problem for me. I had problems with understanding the lectures because here Americans speak very fast and hard for me to understand. (Zulkifli, a male doctoral student majoring in an applied science)

In the first semester, I got a problem with speaking in English from the beginning because you know I do not much like expressions or to start a conversation, or to express a thing. I was not that confident to speak English and my English vocabularies were not that many. It was hard for me to keep speaking for a long time because at that time, I had no clues what to say. (Kamarudin, a male doctoral student majoring in a hard science)

In Indonesia, it is common that students at the university level are passive in the classroom. The data above indicated that participants were shocked with "active classroom" culture. They were unfamiliar with the student-centered instruction at their host university. Their familiarity with "passive classroom” culture or teacher-centered instruction combined with their limited English ability kept them silent in class and made it difficult for them to present assignments in front of a class.

Participants also reported that during their first semester they had difficulties reading material in English in a relatively short period of time, as described by some of the participants:

I wish I could have more time before coming to the classes. You know an international student is required at least to take nine credits hours. It is not easy for me to care of them the first time I started my program. In every class, there are many readings and sometimes it is not easy for me to understand the topic. (Adriani, a female doctoral student majoring in an applied science )

During the first semester, my main difficulty was related to many books and research articles that I had to deal with. Time went fast during the first semester, but I felt I had no time to finish all things like readings, papers, and other kinds of homework. It was stressful time. I think studying in American is more difficult than studying in Europe or in Indonesia. (Zulkifli, a male doctoral student majoring in an applied science) 
In reading, sometimes I missed reading some words and it changed the entire meaning. (Hamdani, a male doctoral student majoring in a hard science)

Their difficulty was related to the fact that in Indonesian academic culture, university students may be accustomed to reading a limited number of book chapters or articles in their classes. Added to the strain of reading more than what they might have been accustomed to, the participants had to read in a foreign language. In addition, although they read course materials, they were not familiar with sharing their ideas in the classroom. Therefore, after participants came to their host university in the US, they found it difficult to keep up with the required readings for each course and actively participate.

Additionally, the Indonesian graduate students in this study reported that writing was one of the major sources of difficulties they faced during the first semester and throughout their studies.

When I was required to write research papers, it appeared to be a problem for me, particularly in writing. I have good English for conversations and for understanding the content of the course, but for writing papers my advisor and collaborators thought I have a problem. My problem is related to how to write a good paper or present my ideas directly in the paper that is in line with the American Academic culture. Writing proposal was really stressful and also I remember when I wrote the first paper for publication was really stressful because one of the professors really paid attention to the correct English and made many revisions for my paper. (Rojuk, a male doctoral student majoring in a hard science)

Well, just to write homework is not a problem. To write a research paper, it is a big problem because I don't know exactly how to write an introduction, how to choose the appropriate words. So, I have a lot of problems in writing my proposal for dissertation. I don't know how to explain my ideas well. (Sabarno, a male doctoral student majoring in a hard science)

Especially writing, it is so difficult until now. Writing is not only about grammar but also about how to organize ideas, coherence, styles, and a good flow. (Suhantono, a male doctoral student majoring in a hard science)

In Indonesia, university students at the undergraduate level are not required to write papers or final papers for every course that they take. Undergraduate students are only required to write a research paper (skripsi) after they finish all the required courses as partial fulfillment of the requirements to get their diploma. After participants of this study came to their host university, they were shocked with the fact that they had to write weekly or final papers in every course they were taking. The situation was complicated by their limited writing skill in English.

Personal Stressors: Temporary Loneliness. Feelings of homesickness and loneliness are common if someone is away from his or her country and family. Based on the within-case and cross-case analyses, Indonesian graduate students who were married reported that they felt lonely and missed their family during the first and second semester.

Before my family came here, I felt a little bit lonely and homesick. I missed them a lot and this influenced my academic situations. That was in the first and second semester. So, those two semesters were very difficult for me. I was very, very stressful. (Mursalin, a doctoral student majoring in an applied science)

Similar feelings were also expressed by some single participants. For example,

If you are in a different place for a long time, the feeling of homesickness or loneliness will always come to you, but the level is different from time to time. In the first three months during the first semester, certainly I felt homesick and lonely. I really missed my family and wanted to go home sometimes. (Leo, a male doctoral student majoring in a hard science)

Yeah, the feeling that disturbed in my first semester is I felt lonely and homesick. You know in Indonesia, I lived with my family or parents. So, when I moved here, I must do everything by myself. It is hard for me. (Kamarudin, a male doctoral student majoring in a hard science)

The data above showed that regardless of their marital status, participants reported that they felt homesick and lonely during their first semester at their host university. For single participants, in Indonesia, it is common for unmarried children to stay with their parents until they get married. As a result, after participants came to their host university, they felt that they experienced a sense of social loss during their first semester. 


\section{Adjustment}

The data indicated that the following factors helped Indonesian graduate students feel less stressed and adjust to their host university from their second semester onward:

- the presence of two non-stressors: (1) the absence of perceived discrimination and (2) absence of financial stress,

- time to learn and adjust to expectations,

- forming supportive relationships, and

- connecting or reuniting with family.

Surprising Non-Stressors. What was surprising from this study is that two salient non-stressors-no sense of cultural or religious discrimination and no reported financial stress-moderated the negative effects of stressors by helping the Indonesian students in this study manage their feelings and avoid seeing stressful events as intolerable problems after the first semester. For no sense of cultural or religious discrimination, all participants reported that they felt they were accepted in a new culture and by people in the host culture, including American students and professors who treated them equally although they were from different cultures. This suggested that they were able to interact with people from different cultures and at the same time they were able to integrate with the host culture, which helped them to adapt successfully to a new culture during their stressful time. This also suggested that their host university promotes multicultural education regardless of students' background.

I do not have real problems with American professors and students. I think they are great although not all of them are good, some of them are great and some are difficult professors to work with. But, I think overall they are really nice. Also, I think American students already know that students from Asia are more quiet and shy. But, they are good and willing to be my friends. American students never reject me. (Rojuk, a male doctoral student majoring in a hard science)

One thing that I like from my university and professors is that since I came here, I have never felt being discriminated in terms of academic issues. I got what I deserved. I also feel that here faculty members have never favored specific student in classroom. American students included me in their activities like they included me in their parties. They also invited me to join them if I wanted to participate in a discussion on a problem related to homework. (Leo, a male doctoral student majoring in a hard science)
From my first semester to my current semester, I have not got any feeling like discrimination or excluded from any academic activities from my professors or American students, particularly at my department, not at all. (Kamarudin, a male doctoral student majoring in a hard science)

If you ask me about discrimination in my department, I would say, no discrimination and I never feel it. I even feel that professors and students in my current department. (Lala, a female doctoral student majoring in a hard science)

All professors here are very well educated and very nice to me. They understand the problems that international students face and they helped me a lot during the first and second semester. American students that I met never do any kinds of discriminations. The only thing is that they do not want to talk first. (Zulkifli, a male doctoral student majoring in an applied science)

Another surprising non-stressor that moderated the negative effects of stressful life events was associated with no financial challenges experienced by Indonesian graduate students at their host university during their first semester and during their university years.

Financial issues are not a problem for me although my salary or payment from my university as a TA [teaching assistant] is not that much, but I think it is enough to cover my expenses of my life here. (Kamarudin, a male doctoral student majoring in a hard science)

I had no problems about money. I mean for my living, it was enough for me. When I had financial problems, I came to Indonesian student to borrow some. (Jauhari, a male doctoral student majoring in a hard science)

Well, the money that I receive from my sponsor every month is sufficient for my life here and my sponsor also pays for my tuitions and fees. (Zulkifli, a male doctoral student majoring in an applied science)

I don't have much money, but I think I am able to manage my money. My department supports me financially starting from first semester to last semester. (Rojuk, a male doctoral student majoring in a hard science)

The findings from this study reveal that all participants in this study reported that during their acculturative process, they did not 
experience financial challenges during their first semester and during their university years. This was caused by the fact that all physics students in this study got funding from their host university and non-physics students won a competitive scholarship awarded by their government or a foreign government to pursue a graduate degree in the US. Such scholarships cover everything including tuition, fees, insurance, housing, plane tickets, and living allowance for their success in studying in the US.

Time to Learn and Adjust to Expectations. Academic and personal stressors decreased overtime. Recovery happened and previous hardships were used to anticipate future challenges at their host university as a result of intercultural and continuous contacts. Starting from their second semester, participants commonly reported that they felt less stressed by academic workload, teaching assistantships, high expectations, and performance anxiety. For example, for academic workload, Antoni, Leo, and Rojuk reported,

I learned a lot from my first semester and I felt better in the second semester. I knew more ways on how to deal with many things. I still had difficulties with homework and assignments, but in general the grades that I got were better. I felt better and better after spending two semesters, I enjoyed my life here. For example, I started enjoying as a TA [teaching assistant]. I can interact with students although homework was still difficult and a lot. (Antoni, a male doctoral student majoring in a hard science)

I felt much better starting from the second semester. Things were more comfortable and I felt I was able to handle academic problems that I had. Well, homework will always be there as long as you take courses. So, homework never stops and still overwhelming. But, you know, I and my friends used the same strategy as we did in the first semester. We teamed up to work on the homework. All students worked together because we faced the same problems related to homework. (Leo, a male doctoral student majoring in a hard science)

Like I said, in the first and second semester, I did well. So, in the third and fourth semester, I started enjoying doing like homework and assignment. But, again they are still difficult. (Rojuk, a male doctoral student majoring in a hard science)

Students with two responsibilities as a full-time graduate student and teaching/research assistant reported that they felt more comfortable managing their demanding academic routine.
It took a while to adjust to this kind of routine, it took about five months to get used to all the workload. Dealing with academic workload, although I was still taking classes and a TA [teaching assistant] in the second semester, it was easier to handle and to adjust with the routine. (Leo, a male doctoral student majoring in a hard science)

In the second semester, I also taught and it was much better because I knew how to teach or present my teaching. It was much easier because I knew the background of the students who I taught. (Sabarno, a male doctoral student majoring in a hard science)

With the exception of writing, participants reported that their listening, reading, oral presentation, and active class participation gradually improved after spending one semester studying at their host university as a result of their socialization with others or of their English training offered by their university.

I was not very good with English. My listening, speaking, reading, and writing were bad in the first semester. I remembered that I could not communicate very well because of my English skill[s]. Sometimes it was hard to follow the discussion. The first semester was the most difficult one [skill] and [...]. However, as the time goes on, I improved my English skills. (Hamdani, a male doctoral student majoring in a hard science)

In general my listening skill is much more improving. I also speak or talk more in the classroom. For reading, I just read materials like what I did in the first semester. So, it is much more on physics stuff. (Kamaruddin, a male doctoral student majoring in a hard science)

During the second semester, my listening skill was better. I could understand American professors and students' talks although I still missed some words that they said. I could better understanding of the lectures. Even in the second semester, when professors speak very fast in the class, I can understand better now. I felt better with my speaking. I felt confident to speak in the classroom and I got improved. Starting from the second semester I have made a lot of improvement in reading. I read faster and understand the course materials better. (Zulkifli, a male doctoral student majoring in an applied science)

However, for some participants writing was still challenging for them. 
Especially writing, it is so difficult until now. Writing is not only about grammar but also about how to organize ideas, coherence, styles, and a good flow. (Suhantono, a male doctoral student majoring in a hard science)

My problem is related to how to write a good paper or present my ideas directly in the paper that is in line with the American Academic culture. Writing proposal was really stressful and also I remember when I wrote the first paper for publication was really stressful. After I started doing research, then I started having problems because in research I had to start writing like prospectus, proposals, papers, and dissertation. (Rojuk, a male doctoral student majoring in a hard science) I started writing research papers in the sixth semester and I stopped taking classes in the ninth semester. When I started writing my proposal, writing was my problem and I think it is the most difficult one. (Kamaruddin, a male doctoral student majoring in a hard science)

Writing is still difficult for me until now and it takes a lot of efforts to do that. (Adriani, a female doctoral student majoring in an applied science)

Forming Supportive Relationships in Host Culture. Indonesian graduate students did not experience or encounter difficulties to form and establish supportive relationship with American professors and students, other international students, and conational students. They enjoyed their relationships and contacts, including the more informal relationships between American professors and students. There is less power distance between professors and students in the US compared to that in Indonesia, which the students seemed to feel comfortable with during the first semester and thereafter. This also suggests that Indonesian students had the ability to build relationships with people from other cultures and had the ability to live in both Indonesian and American culture.

I like the way of how professor-student relationship inside and outside classroom here at my university, especially with American professors. It is more informal. It puts you in a position where you can ask questions or arguments and contribute to any discussions with your professors. I would say it is very positive and outside the classrooms, professors here are always available for you. You just send an email, they will respond to it immediately and if it is a long question, they will set time for you to come. During my first semester, I visited some professors many times and you don't even have to come at their office hours. If you cannot make it, you may send an email and an appointment and they will set time for you. (Suhantono, a male doctoral student majoring in a hard science).

In this study, Indonesian students reported that they had no problems to interact and to make friends with American students. They did not only make friends with American students, but also worked together to solve their academic challenges, suggesting that American students at their host university cared about international students and were willing to socialize with students from other cultures.

I don't think American students are really individualistic. In the academic environment, American students are very cooperative and helpful. They really understand me, I mean because my English is not my first language. From the first semester, I have no problem with American students inside and outside the classroom. So, I think individualism in the American academic culture is not really like what people told me before I came here. People said that American would not care about other people from other cultures. But, I do not know outside the academic culture. I think individualism maybe refer to their lifestyle. American people do not want to know other people's business or private issues. In classroom, American students are very, very cooperative with me. For example, if I ask a question related to academic issues to an American student, he is very welcome to help me although I am not an American. (Mursalin, a male doctoral student majoring in an applied science)

Indonesian students socialized and established good rapport with other international students associated with either academic purposes or other kinds of activities. It suggests that they experienced a sense of cohesion with other students. They had strong connections with students from other cultures. "I made some new friends with other international students. You know we are on the same boat” (Zulkifli, a male doctoral student majoring in an applied science).

Additionally, in this study, participants had strong relationships with other Indonesian students at their host university. They received strong support or counsel from co-national students to overcome life stressors they faced as well as academic stressors or other kinds of problems during their first semester and university years.

I almost know all Indonesian students here because the number is not many and I am fairly close to almost everyone. We feel like we are family here. I always go to see them if I have 
academic or social problems because it is easier to connect with fellow Indonesians. (Suhantono, a male doctoral student majoring in a hard science)

Things are very good until now. We hang out quite often. I think since the number of Indonesian students here is not that many compared to other universities in any other states, we know each other and help each other, which is really good. (Rojuk, a male doctoral student majoring in a hard science)

Indonesian students are like my family here. We visit each other and share our experience. (Lala, a female doctoral student majoring in a hard science)

Connecting or Reuniting with Family. Indonesian graduate students also reported that they felt less homesick and lonely after the first semester. To reduce their loneliness, they made friends with co-national, American, and other international students at their university and department. Regardless of their marital status, participants also indicated that they felt less homesick because they used Skype, Facebook, the telephone, Internet, or Yahoo to maintain relationships with family in Indonesia.

I called my family using Skype and Internet once a week during my time here. That's only way to get in touch with them. I was happy after calling them for one or two hours. (Jauhari, a male doctoral student majoring in a hard science).

Some married students invited their family to come to the US. After their family came to the US, they did not encounter any problems regarding homesickness and loneliness. They just focused on their academic activities.

Before my family came here, I felt a little bit lonely and homesick. I missed them a lot and influenced my academic situations. That was in the first and second semester. So, those two semesters were very difficult for me. I was very, very stressful. But after they came to the US, I could handle my academic matters and family's activities. It's much easier. Basically, I feel comfortable now. (Mursalin, a male doctoral student majoring in an applied science)

\section{Crisis}

Academic Crisis. While all adjusted quickly after they encountered academic shock, many reported that they encountered some sort of academic crises (e.g., conflict with/change of major professors, grades, failed and delayed preliminary exams, writing a dissertation proposal) or personal crises (e.g., death in the family or divorce/marital problems) at some point during their studies. However, participants tended to avoiding talking about their problems and challenges in detail, even though they experienced stressful events. For example, Antoni got into a serious conflict with his major professor, who is not American. He was afraid of reporting his problems to the dean. Rather, he reported it to his department chair; but due to the limited authority of his chair, he decided to quit working with his major professor. As a result, he lost three and half years of work. He finally got a new professor who really supports his work although he had to start from the beginning. He reported,

My academic experience here [at his host university] is rather unique and difficult, you know. I had a problem with my previous major professor. My current professor is very good. He is from Europe. My previous professor was from one of Asian countries. He is probably one of the worse professors. As I told you that I had a problem with my previous major professor [a non-American professor]. I just quit from him. But, I lost three years and half years because of that. But, I survive, you know. I got used to the life here.” (Antoni, a male doctoral student majoring in a hard science)

However, Antoni did not want to talk more about his conflict; he wanted to forget it. Other participants reported that they felt stressed because they had to change their major professors or because they had new major professors. Although they experienced stressful events, they tended to keep these problems and challenges to themselves, which may be related to cultural characteristics in Indonesia that personal problems should not be exposed.

My research adviser had to leave my university. It was really the most stressful time during my program because I had one more year to graduate, but my professor had to leave campus and then the big question was should I continue to work for her? Even though she already left my university or should I transfer to other professor? If I transfer to other professor, I have to redo everything from the beginning, right? So, it was the most difficult time for me. (Rojuk, a male doctoral student majoring in a hard science)

When I got my research advisor, he is an international professor in the third year and he is used to working with postdoc students all the time. So, when I started working with him, it was quite hard because he was impatient to explain 
everything. (Sabarno, a male doctoral student majoring in a hard science)

Another sort of crisis that some participants reported was associated with getting good grades. Lala, a female doctoral student who for three semesters majored in physics and then moved to chemical engineering reported, "You know I was in an academic probation because my GPA [grade point average] was under three and I was supposed to leave.” Doctoral students typically reported that the qualifying or preliminary exam was also one of the areas that made them stressed and some of them reported that they had limited support from their department.

In preliminary exam, I felt lack of preparation because I took the test twice. For the first test, I really had no enough information and guidance from the department. I had no enough support to do the test because the information was not clear. I did not understand about the test. Also the time was very limited. So, I tried to find my own way, but I failed. For the second test, I knew the test and how to do that, but still the support from the department was not enough. I luckily passed because my failure in the first test was a very important lesson for me to do the second test. (Mursalin, a male doctoral student majoring in an applied science)

I delayed my preliminary exam because of my personal problem and my major professor moved to another university. I was so confused because I had to change my research topic again and I had to find a new major professor. I had problems to find my committee members. As an international student, it was difficult to find faculty members who were willing to be my committee. I feel here, a graduate student should do everything by himself or herself. I feel here there is no like certainty and consistency of guidance, rules or academic rules like for preliminary exam or advice for prospectus. If I may say, the support from my department is not really like what I expected before I came here. (Adriani, a female doctoral student majoring in an applied science)

Personal Crises. Findings indicate that despite feeling less stressed by academic stressors and temporary loneliness from their second semester on, several reported that they encountered some sort of personal crises, including death in the family or family problems. These kinds of crises or stressful events challenged and impacted their acculturative process during their university years at their host university. With regard to the issue of death in the family, Rojuk, a male doctoral student majoring in a hard science indicated,
My mother passed away when I was in my second year here. I was really homesick and it really affected my academic performance and my grades in the third and fourth semesters. Also, since I came here, I missed some family events such as wedding or other activities. I just feel sad and bad because I was not there when they needed me.

Additionally, one female participant reported that being away from her close family made it difficult for her to maintain her relationship with her family in Indonesia. Personal crisis with her close family impacted her academic performance. "In the fourth semester, I had a big personal problem. I was so under-pressured and stressed. Some courses that I took were incomplete because of my personal problem" (Adriani, a female doctoral student majoring in an applied science). Even though they experienced stressful events, both Rojuk and Adriani tended to avoid talking about their problems and challenges in detail. They were reticent to share their crises with others, particularly how they dealt with their crises.

One explanation for their reticence to discuss with others or with counseling centers or services at their university is that in Indonesian culture, seeking help from other sources is similar to bringing shame and dishonor to their family. Participants in this study may still maintain these kinds of traditional values, which led them to keep their personal problems and challenges to themselves even though they were under stress. Also in Indonesian culture, if an individual cannot handle his or her own personal problem, it will be seen as a sign of weakness. I assume that their reticence to discuss their problems with me or to use professional services was because they did not want other people know their personal problems. They wanted to be seen as a strong person.

\section{Resolution}

The findings of this study indicate that Indonesian graduate students adapted to the initial academic shock they encountered after spending one semester studying at their host university, suggesting that academic stressors are most prominent in the first semester. Time to learn and to adapt to expectations at their host university has helped them to manage their stressors. They also used previous hardships to anticipate future challenges at their host university. Particularly, starting from their second semester through their university years, Indonesian graduate students regardless of their demographic background commonly reported that they felt less stressed with academic stressors, personal stressors, and language issues.

Their quick adaptation after the first semester was facilitated by forms of assistance (e.g., support from American students and 
professors, no reported financial concerns, or connecting or reuniting with family) that moderated the negative effects of stressors and helped them to adapt and manage their feelings or stressors after the first semester. Specifically, participants in this study received social support not only from people in the host culture, but also from co-nationals and other international students, suggesting that they were able to interact with people from their original culture, and at the same time they were able to integrate with the host culture or interact with other cultural groups to help them adapt successfully to a new culture during their stressful time. Although their rapid adaptation was challenged by some sort of crises, such as conflict with or change of major professors, failed preliminary exams, grades, death in the family, or marital problems, no one left their host university because of the crises, suggesting that they avoided seeing their crises as intolerable problems. It even helped them to become more responsible students. It motivated them to adapt successfully to hardships and it helped them anticipate future challenges at their host university. As one participant said, "I survive, you know. I got used to the life here” (Antoni, a doctoral student majoring in a hard science).

\section{What Helps/Does Not Help or Is/Is Not Utilized?}

The data in this study indicate that there were some factors that did not help or were not used by Indonesian graduate students to adjust to their host university during their acculturative process, including formally organized activities at their host university. Particularly, no one talked about or used counseling services to deal with their stress. "I have no time to do that. Ninety percent of my time at graduate school are for doing homework or assignments. No time is for doing anything else" (Suhantono, a doctoral student majoring in a hard science). Participants typically reported that they used various strategies to cope with their academic crises, including (1) avoiding direct confrontations; (2) seeking help and support from co-national students, American students, other international students, academic and research advisers, faculty members, and family in home country; (3) sleeping, and engaging in physical exercise; and (4) reporting problems to the dean and department chair. However, for personal crises, they were reticent to discuss their problems with other people or to use professional services because in Indonesian culture, seeking help from other sources is similar to bringing shame and dishonor to their family.

\section{Discussion}

Oberg (1960) wrote that during the adaptation or resolution phase, individuals might attain stable adaptation, might acculturate with the host culture including the use of words, gestures, facial expressions, customs, or norms, and might consider them "as just another way of living” (78). According to Berry $(2003,2006)$ and Berry et al. (1987) acculturation as a process of adapting to a new culture, including behavioral changes (e.g., language skills and social skills) and internal characteristics (e.g., values, beliefs, norms, and attitudes) that occur during the acculturating process. Acculturating individuals face acculturative problems (i.e., stressors) as a result of intercultural and continuous contact that cannot be solved easily and quickly by simply adjusting or adapting to the new cultures. However, "as a result of attempts to cope with these acculturation changes [stressors], some long-term adaptations may be achieved” (Berry 2006, 295). Relatively stable changes may occur in acculturating individuals in response to external demands (Berry 2006). The acculturating individuals know what to expect in most situations, how to manage cultural difficulties, and how to resolve the problems in the host culture.

The findings of this study shed light on our understanding of international students' acculturative processes, particularly Indonesian graduate students from the perspective of Oberg's (1960) Culture Shock Theory, Berry and his colleagues’ (1987), and Berry's (2006) Acculturative Stress Model that takes into account students' diverse backgrounds and experiences, major sources of acculturative problems, and strategies used during their acculturative process in a different culture during the first term and over time at their host university. How are the findings of this study related to the theoretical framework used in this study? Are the findings consistent or inconsistent with the theories?

\section{Findings in Relation to Theoretical Framework}

From the perspective of Oberg's (1960) culture shock theory, when individuals enter a new culture, they encounter four common stages of culture shock: the honeymoon or traveler phase, the crisis phase, the adjustment and gradual recovery phase, and the adaptation phase (Oberg 1960; Winkelman 1994). For example, in the honeymoon or traveler phase, individuals who enter a new culture are like those who visit other cultures for their honeymoon, holidays, or business. They enjoy the differences between the home and the host culture including new foods, people's habits, the buildings, and the language. Although they might experience anxiety and stress, they see the difference in a romantic light, as interesting, amazing, and exciting (Oberg 1960; Winkelman 1994). However, findings from this study indicate that the common processes experienced by the 13 Indonesian graduate students during their acculturative processes were slightly different from Oberg's (1960) stages of culture shock. The common processes that they encountered were academic shock-no 
honeymoon, adjustment, crisis, resolution, and what helps/does not help or is/is not utilized. For example, due to the differences between academic culture in the US and Indonesia participants in this study did not encounter a honeymoon phase during their acculturation processes in their first semester. They directly faced academic shock or they encountered what Berry (2006) and Berry et al. (1987) called "acculturative stressors."

From the perspective of the Berry acculturative stress model, an acculturating individual may face many to a few stressors as a result of varying acculturative experiences; for some acculturating individuals, the acculturative changes in routine patterns of behavior and internal characteristics in their lives may become stressors, whereas for others, the changes may be benign or may be considered as opportunities (Berry et al. 1987; Berry and Kim 1987; Berry 2006) because there are non-stressors that modify the impacts of the changes. In addition, Berry and Uicho Kim (1987) and Berry, Kim, and their colleagues (1987) conclude that the acculturative problems or stressors depend on factors or variables that moderate the relationship between acculturation and stress. Although the Indonesian graduate students reported that they encountered stressful life events that arose from academic and personal stressors during their first semester, the findings of this study indicate that there were coping mechanisms and surprising non-stressors (e.g., access to supportive relationships or no financial concerns) that moderated the negative effects of stressful events and helped them manage their feelings or stressors and avoid seeing stressful events as intolerable problems after the first semester. Berry (2006) stated, "Acculturation has both positive (e.g., opportunities) and negative (e.g., discrimination) aspects” (294). Although Indonesian graduate students face acculturative problems or stressors as a result of unanticipated differences and difficulties in cultural encounters, recovery happened and previous hardships were used to anticipate future challenges at their host university as a result of intercultural and continuous contacts. Starting from their second semester throughout their time at their university, participants commonly reported that they felt less stressed. In addition, despite the fact that many encountered some sort of crises, the findings of this study indicate that no one left their host university because of the crises, suggesting that they knew what to expect in most situations, how to manage cultural difficulties, and how to resolve the problems in the host culture.

\section{Findings in Relation to Previous Research}

Academic Stressors. Indonesian graduate students reported that academic workload (e.g., homework and reading literature) and teaching/research assistantships were two major stressors they encountered. These results are consistent with what Yu-Wen Ying
(2005) found in that homework was one of the acculturative stressors for Taiwanese international graduate students and what Takahiro Sato and Samuel R. Hodge (2009) found in their study on Asian students, including students from Japan, South Korea, and Taiwan. They struggled to manage time to carry out multiple tasks such as teaching, coursework, and research. Other major academic stressors that were typically reported by participants in this study were professors' high expectations and pressure to perform well, which is consistent with what Sato and Hodge found in terms of academic troubles. The Asian students in their study struggled to meet their academic advisors' academic related expectations and priorities. Some Indonesian graduate students in this study reported that they had a serious conflict with non-US faculty. Although Sato and Hodge did not specifically mention the origin of advisers in their study, they also found that some participants felt dissatisfied with their academic advisors. However, after Indonesian graduate students finished their first semester, they felt more adjusted to the academic culture at their host university and their level of stress gradually reduced, suggesting that acculturative stressors are most prominent in the first semester. This finding supports what Ying (2005) found as well in that acculturative stressors are most intense immediately upon arrival.

Language Barriers. Indonesian graduate students reported that they faced language problems. This finding is consistent with the findings of previous studies that found language barriers as one of the major acculturative stressors for international students at their host university (Zhai 2002; Yeh and Inose 2003; Poyrazli, Kavanaugh, Baker, and Al-Timimi 2004; Fritz, Chin, and DeMarinis 2008; Sumer, Poyrazli, and Grahame 2008). Yet, previous studies often fail to specifically describe what language skills become barriers for international students to succeed in their academic and social life and how long they experience such problems. In this study, I found that participants indicated that they had language difficulties related to listening, reading, writing, and oral presentation. Given Lee (2009) found that Korean graduate students felt their lack of English proficiency was the most critical factor influencing their oral participation in graduate class discussions. Soonhyang Kim's (2006) study indicated that East Asian international graduate students were most concerned about leading class discussions and participating in whole-class discussions because of their limited English ability. Additionally, what I found is consistent with Alwasilah (1991) who found that Indonesian students had language problems when it came to writing research papers and making oral presentations. However, Alwasilah's (1991) study did not clearly mention whether language problems decreased overtime or not. Unlike previous 
studies, however, except for writing, in this study, participants typically reported that their language skills gradually improved after spending one semester studying at their host university as a result of their socialization with others or of their English training offered by their university.

Social Support. Previous studies documented that international, Asian students in particular tended to have issues socializing and therefore getting support from their native English speaking peers and other international students. For example, a study done by Andrea G. Trice $(2004,683)$ indicated that students coming from East and Southeast Asia "were generally quite concerned about functioning in the American culture and establishing American friendships.” Additionally, Marie V. Fritz, Dorothy Chin, and Valerie DeMarinis (2008) in their survey study found that Asian students found it harder to make new friends.

However, unlike the findings of the previously mentioned studies, this study revealed that Indonesian graduate students did not experience stressful events related to forming supportive relationships with people in the host university, other international, and co-national students. The findings of this study indicated that participants received support not only from people in the host culture (e.g., American professors and students), but also from conationals and other international students. This finding is consistent with the findings of previous studies. For example, Seda Sumer, Senel Poyrazli, and Kamini Grahame's (2008) study showed that lack of social support contributed to depression and anxiety among international students. Students with lower levels of social support reported higher levels of depression and anxiety, suggesting that higher levels of social support might enable international students to be more socially active and interact with people more often and, as a result, reduce feelings of depression and anxiety. Roger Y. Klomegah (2006) also indicated that social contact was significantly associated with alienation. International students who had regular contact with other students-foreign, host, or from the same region-were less alienated from the college environment than those who had fewer contacts with others. Poyrazli, Philip R. Kavanaugh, and their colleagues (2004) found that international students who primarily socialized with other international students experienced more acculturative stress than did international students who interacted with both American students and non-American students. Christine J. Yeh and Mayuko Inose's (2003) study also indicated that acculturative stress was significantly determined by social support satisfaction and social connectedness. International students who felt less socially connected and were less satisfied with their social networks experienced more acculturative stress. The-yuan Wan, David W. Chapman, and Donald A. Biggs (1992) reported that international students with a stronger social support network in their new academic environment tended to experience less stressful in academic situations than did students with less well-developed social networks.

Financial Challenges and Discrimination. Madonna G. Constantine and her colleagues (2005), Charles P. Chen (1999), and Jun-Chih G. Lin and Jenny K. Yi (1997) indicated that financial challenges were one of the major sources of acculturative stressors or problems for international students. However, in this study, all participants reported that during their acculturative process, they did not experience financial challenges during their first semester or during their university years. This is due to the fact that all physics students in this study received funding from their host university and non-physics students were awarded a competitive scholarship by their government or a foreign government to pursue graduate study in the US. Additionally, Jenny J. Lee and Charles Rice (2007) and Constantine and her colleagues (2005) found that the discrimination international students faced from people at their host institution added to their acculturative problems. However, in this study, Indonesian graduate students reported that they felt they were accepted in the new culture and by people in that culture, including American students. Professors treated them equally although they were from different cultures, suggesting that their host university promotes multicultural education regardless of students' backgrounds.

\section{Limitations}

While this study will potentially contribute to the sort of evidence necessary for providing support in terms of academic and non-academic programs and policies to university policymakers who need to facilitate Indonesian or other international students' adjustment to their new academic and social culture, this study has several limitations regarding the findings. First, as an insider, someone who was an Indonesian graduate student at a US flagship university at the time of this study, I was able to gain a deeper understanding of the acculturative experience issues revealed in the findings and analyses. On the other hand, such insider status potentially became a source of subjective bias. I attempted to limit potential bias through triangulation, member checks, and rich and thick description of the topic (Merriam 1998; Creswell 2003). Second, owing to logistical limitations, I was not able to undertake a more prolonged process of interaction with the participants and therefore unable to do multiple interviews over a longer period of time. This may limit the depth of information obtained and participants' openness to discuss their thoughts, feelings, and perspectives on their acculturation process. Third, Indonesian 
graduate students were recipients of various scholarship programs, including scholarships from the Indonesian government, the US government, and graduate assistantships from the host university. Having financial assistance may have reduced the graduate students' reported level of acculturative difficulties or problems during their first semester or throughout their university years at their host university. Last, the findings of this study were based on a demographic survey, individual interviews and focus groups discussions. The participants' feelings, thoughts, reflections, and perspectives on their academic and social acculturative experiences might be different from their actual acculturative experiences. What I believed to be their reticence in sharing their actual experiences with me might be related to Indonesian culture in that private problems are typically shared with family only. Another explanation is that they might not want to remember their problems (at home) during their life in a new culture with others.

\section{Implications for Future Higher Education Research, Policy, Program, and Practice}

\section{For Future Research}

First, in this study, participants may not be representative of all Indonesian graduate students in the US. There may be differences between the acculturative experience or culture shock faced by Indonesian students who are enrolled in different programs, nondegree to post-doctoral programs, and who are self-financing students. Future research may include a larger sample of Indonesian graduate students from different universities in the US, which may provide different perspectives, feelings, and thoughts of Indonesian graduate students' acculturative experiences. Second, given that faculty, staff, and administrators were excluded from this study, future research could investigate the faculty and staff's perspectives on Indonesian graduate students and their awareness of the issues that international students face during their acculturative process. Third, it is evident from this study that acculturative problems or stressors are most important during participants' first semester and gradually reduce after the first semester. Future research could investigate whether the duration of stress experienced by Indonesian students applies to other Indonesian and international students in US universities. Finally, in this study, American students were not included. Future researchers could include the voices of American students on Indonesian graduate students or other international students' acculturative processes.
For Student Affairs Professionals (e.g., directorate general of higher education office, or government agencies) Working with Graduate Students in Indonesia

The findings from this study indicate that participants lacked knowledge of American academic and social life before they came to the US. The knowledge they did have, they gained from television or Internet, suggesting that much of the information they learned on American academic and social culture was during their time at their host institution. Consequently, they faced several acculturative problems during their first semester. Government agencies and student affairs professionals working with Indonesian students who want to study in the US should provide them with clear information on American academic and social culture. The focus should be on assisting Indonesian students in understanding social rules, norms, traditions, and values that rule interaction and communication in American higher education, including academic workload, faculty expectations, the nature of relationships with professors and advisers, and classroom dynamics. The findings of this study indicate that reuniting with family could reduce the levels of stress for participants who were married and left their family in their home country. The sending institution and the receiving institution should facilitate the process of reuniting international students with their family. Other findings indicate that the cohort effect was strong. Indonesian graduate students received strong support or counsel from conational students to overcome life and academic stressors or other kinds of problems during their first semester and university years. For government agencies and non-government organizations that sponsor Indonesian students to study in US universities, it might be better to send Indonesian students in small groups of three or five students to the same university rather than sending one student to an institution where there is likely to be no support from co-national students.

\section{For Departments and Universities in the United States}

The findings from this study indicate that due to the differences in educational systems between Indonesia and the US, acculturative problems or stressors seem to be most important during participants' first semester then gradually reduce thereafter. Upon arrival and during the first semester, departments and universities could provide programs for helping international students understand cultural norms of American higher education such as classroom behavior, the nature of relationships with professors and advisers, teaching styles, academic workload, expectations, class dynamics, and study requirements. Second, findings from this study also indicate that some participants had 
problems with faculty members (e.g., conflicts with non-American professors and perceptions of unfair treatment). Departments or universities could provide contact people at the departmental level who will help international students deal with problems with faculty members. In addition, departments and universities should provide cross cultural training programs for non-American professors to increase their awareness of other cultures. Additionally, it is evident in this study that participants tried to handle their acculturative problems directly. For example, one student who failed his doctoral preliminary exam did not look for help from his department. Or Adriani, who had a personal problem with her family in Indonesia, was reticent to go to the counseling center at her host university. Even though it is good for students to show their independence, it is quite risky if they fail to overcome a problem and it may lead them to be more stressed. Departments could use senior international students from the same country to introduce first year students to the rules, procedures, expectations, academic workload, and other academic and social issues that would allow new students access to valuable university resources (e.g., mentoring, student activities, workshops, or training) at their host university.

\section{For Faculty Members and Advisers}

The findings also could be utilized by advisers or faculty members to better understand, advise, and assist international students in having a more successful acculturative experience, hence transition, to their university life in the US. Participants in this study had problems, including failed preliminary exams, grades, and conflicts with non-American professors. Faculty members and advisers should take the lead in connecting with international students because these students will not always turn to their professors or advisers and most likely will wait for a professor to initiate communication during the first semester or later. Some recommendations for faculty members include facilitating regular meetings with students to share perspectives and voice concerns or providing structured academic advising sessions for advisees during offices hours. Also, the findings of this study show that during their first semester, Indonesian graduate students majoring in social sciences and education encountered academic shock related to academic workload (e.g., a lot of homework or reading assignments). Advisers or faculty members should advise international students not to take advanced courses during their first semester or first year.

\section{For International Offices}

It takes time for international students to adjust to their new academic and social environment because of cultural differences and other factors (e.g., level of English proficiency and academic workload). The findings from this study indicate that participants reported that they were isolated from socially or culturally purposeful campus activities (i.e., activities that are officially provided by their host university so students are able to mix with students from other countries) due to high expectations and an overwhelming academic workload. The international office should provide social or cultural programs for international students and their faculty members or advisers to reduce their work-related stress. Oftentimes, programs are created to accommodate the clubs, fraternities, and sororities for undergraduate students, while programs for graduate students are few. The international office should pay more attention to the needs of older students as well so they can be involved in socially or culturally purposeful campus activities (e.g., sponsoring celebrations of different cultures; holding seminars that encourage open dialogue to share feelings, perspectives, and experiences; or scheduling social events where students and faculty members participate in culturally relevant activities together). The international office should also provide programs for helping international students better understand social rules, norms, traditions, and values that rule interaction and communication in American higher education, including academic workload, faculty expectations, the nature of relationships with professors and advisers, and classroom dynamics upon arrival and during the first year. Finally, the international office should make efforts to advertise resources international students can utilize before, upon arrival, and throughout their time at the institution and as alum (e.g., writing center, programs, and workshop). Also, the international office and respective departments should help international students improve their English by providing programs or workshops that develop their spoken and written English. For example, programs that provide conversation partners or assistance with writing, or workshops that address plagiarism and effective presentations.

\section{Conclusion}

Utilizing a phenomenological approach and Oberg's (1960) Culture Shock Model and Berry and his colleagues' (1987) and Berry's (2006) Acculturation Stress Model, this qualitative study aims to describe and understand the lived experiences of the acculturative process of Indonesian graduate students at a US public research university. Findings offer insights into what Indonesian students experience during their acculturation process 
at their host culture and extend the work of Alwasilah (1991) who found that Indonesian university students studying at higher education institutions in the US encounter academic and social challenges. Expanding on this research is particularly relevant given the dramatic advances in access to and content and means of communication over the past few decades, all of which have potential to influence the acculturation of Indonesian university students at higher education institutions in the US. Although findings are similar in that participants from both time periods faced challenges related to using English for academic purposes, working with advisors, and understanding American culture and values, this study reveals that from their second semester onward participants commonly reported feeling less stressed. This suggests that acculturative stressors are most prominent in the first semester. Stressors seemed to be moderated by supportive relationships, connecting or reuniting with family, a lack of perceived discrimination, and an absence of financial concerns, thus facilitating adaptation after the first semester. Five common processes the Indonesian graduate students in this study seemed to go through are academic shock/no honeymoon, adjustment, crisis, resolution, and what helps/does not help? These processes coupled with specific mediating factors seem not only to facilitate acculturation, but do so within a relatively short period of time.

\section{References}

Abe, Jin, Donna M. Talbot, and Robyn J. Geelhoed. 1998. "Effects of a Peer Program on International Student Adjustment.” Journal of College Student Development 39 (6): 539-547.

Association of Public and Land-Grant Universities. 2011. The U.S. and Indonesian Presidents Cite Indonesia Higher Ed Council in Joint Declaration. Washington, DC: A Public Voice, the Association of Public and Land-Grant Universities. Available online at: http://www.aplu.org.

Awasilah, Adeng Chaedar. "Cultural Transfer in Communication: A Qualitative Study of Indonesian Students in U.S. Academic Settings.” Doctoral's Dissertation, Indiana University, 1991.

Berry, John W. 2003. "Conceptual Approaches to Acculturation.” In Acculturation: Advances in Theory, Measurement and Applied Research, ed. Kevin M. Chun, Pamela B. Organista, and Gerardo Marín (pp. 17-37). Washington, DC: American Psychological Association.

Berry, John W. 2006. “Acculturative Stress.” In Handbook of Multicultural Perspectives on Stress and Coping: International and Cultural Psychology Series, ed. Paul T. P. Wong and Lillian C. J. Wong (pp. 287-298). New York: Springer.
Berry, John W., Uicho Kim, Thomas Minde, and Doris Mok. 1987. "Comparative Studies of Acculturative Stress." International Migration Review 21 (3): 491-511.

Berry, John W., and Uicho Kim. 1987. “Acculturation and Mental Health.” In Health and Cross - Cultural Psychology, ed. Piere R. Dasen, John W. Berry, and Norman Sartorius (pp.207- 238). Newbury Park. CA: Sage Publications.

Chen, Charles. P. 1999. "Common Stressors Among International College Students: Research and Counseling Implications.” Journal of College Counseling 2 (1): 49-65.

Chen, Hwei-Jane, Brent Mallinckrodt, and Michael Mobley. 2002. "Attachment Patterns of East Asian International Students and Sources of Perceived Social Support as Moderators of the Impact of U.S. Racism and Cultural Distress.” Asian Journal of Counseling 9 (1 \& 2): 27-48.

Constantine, Madonna G., Gregory M. Anderson, LaVerne A. Berkel, Leon D. Caldwell, and Shawn O. Utsey. 2005. "Examining the Cultural Adjustments Experiences of African International College Students: A Qualitative Analysis.” Journal of Counseling Psychology 52 (1): 3-13.

Creswell, John W. 1998. Qualitative Inquiry and Research Design: Choosing among Five Traditions. Thousand Oaks, CA: Sage Publications.

Creswell, John W. 2003. Research Design: Qualitative, Quantitative, and Mixed Methods Approaches. Thousand Oaks, CA: Sage Publications.

Creswell, John, W. 2007. Qualitative Inquiry and Research Design: Choosing among Five Traditions. 2nd ed. Thousand Oaks, CA: Sage Publications.

Fritz, Marie V., Dorothy Chin, and Valerie DeMarinis. 2008. "Stressors, Anxiety, Acculturation, and Adjustment among International and North American Students.” International Journal of Intercultural Relations 32: 244-259.

Glesne, Corrine. 1998. Becoming Qualitative Researchers: An Introduction. 2nd ed. New York: Longman.

Heggins, Willie J., and Jerlando F. L. Jackson. 2003. "Understanding the Collegiate Experience for Asian International Students at a Midwestern Research University.” College Student Journal 37 (3): 379-391.

Institute of International Education (IIE). 2010. Open Doors 2010 Report: Information and Data Tables. New York: IIE. Available online at: http://www.iie.org.

IIE. 2011. Open Doors 2011 Report: Information and Data Tables. New York: IIE. Available online at: http://www.iie.org. International Center. 2008. International Student Handbook 20082009. Tallahassee: Division of Student Affairs, Florida State University. 
Johnson, Burke, and Larry B. Christensen. 2008. Educational Research: Quantitative, Qualitative, and Mixed Approaches. 3rd ed. Boston: Sage Publications.

Kim, Soonhyang. 2006. “Academic Oral Communication Needs of East Asian International Graduate Students in Non-Science and Non-Engineering Fields.” English for Specific Purposes 25: 479-489

Klomegah, Roger Y. 2006. "Social Factors Relating to Alienation Experienced by International Students in the United States.” College Student Journal 40 (2): 303-315.

Lee, Given. 2009. "Speaking Up: Six Korean Students' Oral Participation in Class Discussions in US Graduate Seminars." English for Specific Purposes 28: 142-156.

Lee, Jenny J., and Charles Rice. 2007. "Welcome To America? International Student Perceptions of Discrimination.” Higher Education 53: 381-409.

Lee, Jee-Sook, Gary F. Koeske, and Esther Sales. 2004. "Social Support Buffering of Acculturative Stress: A Study of Mental Health Symptoms Among Korean International Students.” International Journal of Intercultural Relations 28: 399-414.

Li, Andrew, and Michael B. Gasser. 2005. "Predicting Asian International Students' Sociocultural Adjustment: A Test of Two Mediation Models.” International Journal of Intercultural Relations 29 (5): 561-576.

Lin, Jun-Chih G., and Jenny K. Yi. 1997. “Asian International Students' Adjustment: Issues and Program Suggestions.” College Student Journal 31(4): 473-479.

Lincoln, Yvonna S., and Egon G. Guba. 1985. Naturalistic Inquiry. Newbury Park, CA: Sage Publications.

Marklein, Mary. B. 2011. U.S. Colleges' Appeal Fading for Foreign Students. McLean, VA: USA Today. Available online at: http://www.usatoday.com.

Marshall, Catherine, and Gretchen B. Rossman. 1999. Designing Qualitative Research. 3rd ed. Thousand Oaks, CA: Sage

Merriam, Sharan B. 1998. Qualitative Research and Case Study Applications in Education. San Francisco, CA: Jossey-Bass.

Miles, Matthew B., and Michael A. Huberman. 1994. Qualitative Data Analysis: An Expanded Sourcebook. San Francisco, CA: Sage Publications.

Moustakas, Clark E. 1994. Phenomenological Research Methods. Thousand Oaks, CA: Sage Publications.

Nilsson, Johanna E., Jenay Butler, Sarah Shouse, and Chetan Joshi. 2008. "The Relationships among Perfectionism, Acculturation, and Stress in Asian International Students.” Journal of College Counseling 11 (2): 147-158.

Oberg, Kalervo. 1960. "Culture Shock: Adjustment to New Cultural Environments.” Practical Anthropology 7: 177-182.
Patton, Michael Q. 1990. Qualitative Evaluation and Research Methods. Thousand Oaks, CA: Sage.

Perrucci, Robert, and Hong Hu. 1995. "Satisfaction with Social and Educational Experiences among International Graduate Students.” Research in Higher Education 36 (4): 491-508.

Polkinghorne, Donald E. 1989. "Phenomenological Research Methods.” In Existential-Phenomenological Perspectives in Psychology, ed. Ronald S Valle, Steen Halling, and James F T Bugental (pp. 41-60). New York: Plenum.

Poyrazli, Senel, Philip R. Kavanaugh, Adria Baker, and Nada AlTimimi. 2004. "Social Support and Demographic Correlates of Acculturative Stress in International Students." Journal of College Counseling 7: 73-82.

Rothkopf, David. 1997. "In Praise of Cultural Imperialism.” Foreign Policy 107: 38-53.

Sato, Takahiro, and Samuel R. Hodge. 2009. “Asian International Doctoral Students' Experiences at Two American Universities: Assimilation, Accommodation, and Resistance.” Journal of Diversity in Higher Education 2 (3): 136-148.

Sumer, Seda, Senel Poyrazli, and Kamini Grahame. 2008. "Predictors of Depression and Anxiety among International Students.” Journal of Counseling \& Development 86 (4): 429437.

Toyokawa, Neru, and Noriko Toyokawa. 2002. "Extracurricular Activities and the Adjustment of Asian International Students: A Study of Japanese Students. International Journal of Intercultural Relations 26 (4): 363-379.

Trice, Andrea G. 2004. "Mixing it Up: International Graduate Students' Social Interactions with American Students.” Journal of College Student Development 45 (6): 671-687.

Wan, Teh-yuan, David W. Chapman, and Donald A. Biggs. 1992. "Academic Stress of International Students Attending U.S. Universities.” Research in Higher Education 33 (5): 607-623.

Wei, Meifen, Michael J. Mallen, Paul Heppner, Tsun-Yao Ku, Kelly Yu-Hsin Liao, andTsui-Feng Wu. 2007. “Acculturative Stress, Perfectionism, Years in the United States, and Depression among Chinese International Students.” Journal of Counseling Psychology 54 (4): 385-394.

Winkelman, Michael. 1994. "Cultural Shock and Adaptation." Journal of Counseling and Development 73 (2): 121-126.

Wilton, Leo, and Madonna G. Constantine. 2003. "Length of Residence, Cultural Adjustment Difficulties, and Psychological Distress Symptoms in Asian and Latin American International Students.” Journal of College Counseling 6: 177-186.

Yeh, Christine J., and Mayuko Inose. 2003. International Students' Reported English Fluency, Social Support Satisfaction, and Social Connectedness as Predictors of Acculturative Stress.” Counseling Psychology Quarterly 16 (01): 15-28. 
Ying, Yu-Wen. 2005. "Variation in Acculturative Stressors over Time: A Study of Taiwanese Students in the United States." International Journal of Intercultural Relations 29: 59-71.

Zhai, Lijuan. 2002. "Studying international students: Adjustment issues and social support.” San Diego: Office of Institutional Research, San Diego Community College District. 